Jasmina Markič

Facultad de Filosofía y Letras

Universidad de Ljubljana

Eslovenia

jasmina.markic@ff.uni-lj.si
UDK 811.134.2'366.587:82Vallejo F.

DOI: $10.4312 /$ vestnik.13.227-241

\title{
SOBRE LAS PERÍFRASIS VERBALES DE GERUNDIO EN LA RAMBLA PARALELA DE FERNANDO VALLEJO
}

«Todo pasa, todo se olvida, nada queda.» Fernando Vallejo (2002: 132)

Uno de los temas recurrentes de la novela La Rambla paralela del escritor colombiano Fernando Vallejo (Medellín, 1942) es el paso del tiempo en el que el presente y el pasado se diluyen en un futuro que lleva a la muerte: «Su memoria sería sucesiva pero él era simultáneo, con una simultaneidad rabiosa que abarcaba el pasado, el presente y el futuro [...]» (LRP 181) ${ }^{2}$. Es una de sus novelas autobiográficas en la que el protagonista/narrador es también Fernando, su alter ego, como ocurre en La virgen de los sicarios, El desbarrancadero y otras obras. En la expresión del fluir imparable del tiempo, las perífrasis verbales (a continuación p.v.) de gerundio desempeñan un papel importante en el estilo vallejiano.

Uno de los paralelismos más destacados en la novela es el juego de voces narrativas. En La Rambla paralela el protagonista dialoga con su alter ego ${ }^{3}$ : "El sol se puso en camino y el viejo llegó al hotel con las primeras sombras, a nada, a no dormir, a seguir en su diálogo de sordos consigo mismo» (LRP 47). La Rambla paralela empieza con el protagonista en primera persona como si se tratara de una crónica y no de ficción. Unas líneas

\footnotetext{
1 Este estudio ha sido realizado en el marco del programa de investigación P 6-218, Teoretične in aplikativne raziskave jezikov. Kontrastivni sinhroni in diahroni vidiki (Investigaciones teóricas y aplicadas de las lenguas. Aspectos sincrónicos y diacrónicos) financiado por ARRS.

2 Las citas de la novela llevan entre paréntesis las iniciales del título $(L R P)$ seguidas del número de la(s) página(s).

3 El narrador y protagonista de sus novelas se llama Fernando (apodado «el Viejo») y comparte muchos hechos biográficos del autor Fernando Vallejo.
} 
más abajo el protagonista se transforma en un narrador de tercera persona sin llegar a ser un narrador omnisciente. Forero Gómez lo llama «narrador flotante»:

Hacia el final de la novela, el narrador en tercera persona se convierte momentáneamente en un narrador en primera persona plural ${ }^{4}[\ldots]$ y luego en primera persona $[\text { singular }]^{5}[\ldots]$ con la intención de sugerir una cercanía física con Fernando; sin embargo, el narrador vuelve a la tercera persona poco después y mantiene durante todo el momento su rol como la conciencia del protagonista. Con este juego de voces narrativas, Vallejo logra hacer más difusa o diluida la presencia del yo de Fernando [...]. (Forero Gómez 2011: 18-19)

El título de la obra, La Rambla paralela, es significativo e implica un paralelismo en el que se encuentra el protagonista que se mueve entre la vida y la muerte, entre su presente y su pasado, entre Barcelona y Colombia: «La metáfora de la rambla 'paralela' en oposición a la rambla de la ciudad, le permite recrear el mundo del recuerdo con el mismo valor que el mundo real de la Feria y de Barcelona» (Forero 2005: 49). Fernando deambula por Barcelona y por sus recuerdos como un fantasma. La voz del teléfono al inicio de la novela le dice que ya está muerto: «Todos nos tenemos que morir, hombre, no sea bobito. Es más: ahí donde está usté, en su cama, también ya está muerto. Vaya mírese en el espejo y verá. ¡Levántese!» (LRP 10).

\section{3}

\section{EL PAPEL DE LAS PERÍFRASIS VERBALES DE GERUNDIO}

Uno de los temas recurrentes ligado a la muerte, al recuerdo y al olvido, como ya se ha señalado, es el paso del tiempo. El fluir del tiempo se expresa a menudo con los verbos de movimiento, tanto en su uso pleno como en su uso metafórico o como verbos auxiliares de perífrasis. Ir y venir, como verbos plenos $(1,2,3,4)$ o sustantivos $(3,4)$, se repiten a lo largo de la novela para indicar un movimiento repetitivo de ida y vuelta, ya que los dos verbos indican direcciones opuestas ${ }^{6}$ :

$1 \quad-$ Venían pues ustedes como sardinas en caja de sardinas. (LRP 15)

2 Iba entre la multitud oyendo sin oír, viendo sin ver, tratando de recordar, de volverse a encontrar en el muchacho que un día fue, de recuperarse a sí mismo. (LRP 21)

4 «Estábamos con él en el Café de la Ópera cuando oscureció, hacia las diez de la noche. En Barcelona en verano el sol se pone tarde y los días duran mucho, cosa que a nosotros, los provincianos del trópico que vivimos en permanente equinoccio, se nos hace raro». (LRP 185)

5 «Mi último recuerdo de él es alejándose por las Ramblas en la noche entre el gentío». (LRP 185)

6 Las cursivas en los ejemplos citados en este artículo son nuestras. 
3 Iban y venían, de la Plaza de Cataluña a la glorieta de Colón, y de la glorieta de Colón a la Plaza de Cataluña. Tal su forma de llenar sus vidas, en un ir viniendo. (LRP 86)

La Rambla paralela ${ }^{7}$ se sitúa en espacios (la Rambla de Barcelona, por una parte, y la calle Junín en Medellín, por otra) y tiempos (presente, pasado y futuro) paralelos. En el ejemplo 4 aparece el paralelo entre el pasado (la calle Junín en Medellín) y el presente (la Rambla en Barcelona) con la imagen del tiempo como un péndulo de reloj.

4 [...] la Rambla afuera, a unas cuadras, seguía en su ir y venir empecinado, yendo y viniendo, yendo y viniendo, como en sus buenos tiempos Junín.

-¿Sí te acordás de Junín?

¡Cómo olvidarla! Por esa calle bulliciosa de la ciudad inefable había transitado, del Parque de Bolívar a la Avenida La Playa y de vuelta de ésta a ése como un péndulo idiota de reloj, su juventud inútil. ¿Hacía cuánto? (LRP 17)

Las p.v. de gerundio ${ }^{8}$ «muestran una acción, un proceso o un estado en su curso» (NGLE 2009: 2185) e indican diferentes valores tempoaspectuales y modales. El auxiliar de las p.v. de gerundio es frecuentemente un verbo de movimiento. El proceso de vaciado o gramaticalización ${ }^{9}$ no suele ser total en los verbos de movimiento y el verbo en su uso auxiliar suele conservar algunos rasgos semánticos del verbo pleno (Batiukova y De Miguel 2013: 446), es decir, aunque pierden parcial o totalmente su valor pleno de movimiento, estos verbos que actúan como auxiliares mantienen un matiz de dinamicidad que confieren a las p.v. en sus valores tempoaspectuales. Sus rasgos se prestan a usos estilísticos para marcar el paso del tiempo.

La p.v. ir + gerundio $^{10}$ expresa la progresión, el desarrollo gradual de un evento y suele ir acompañada de adverbiales que refuerzan la intensificación gradual (paulatinamente, progresivamente, gradualmente, poco a poco). Tiene un fuerte valor expresivo y se usa a menudo para describir y/o acentuar el lento progresar de las acciones y para inmovilizarlas en el tiempo. Señala tanto la perspectiva global como la cursiva ${ }^{11}$,

7 En Barcelona no existe una Rambla Paralela sino que hay dos calles: la Rambla/les Rambles, un paseo que va desde la Plaza de Cataluña/Plaça de Catalunya al puerto antiguo, y la Avenida del Paralelo/Avinguda del Parallel que une las Atarazanas Reales de Barcelona/Drassanes Reials de Barcelona a la Plaza de España /Plaça de Espanya.

8 La p.v. de gerundio es la unión directa (sin preposición o conjunción) de un verbo auxiliar flexionado y un gerundio (forma no personal o no flexionada en su carácter verbal y no adverbial o adjetival) que forman un solo núcleo verbal. «El significado propio de la perífrasis surge de la conjunción del auxiliar y el gerundio y no se reduce a la suma del significado de sus dos componentes.» (Yllera 1999: 3393). Véase también NGLE (2009: 2185) y Gómez Torrego (1988).

9 «Esa relativa vacuidad (o facilidad para 'vaciarse') es precisamente lo que los capacita para entrar a formar parte de perífrasis como verbos auxiliares desemantizados.» (De Miguel 2012: 189).

10 Para las p.v. de gerundio con ir y venir como auxiliares, véase también Markič (2020: 353-355).

11 La definición general del concepto de valores aspectuales se desprende de las definiciones de aspecto de los autores Miklič (1983), Comrie (1976), Coseriu (1980), García Fernández (2006) entre otros. 
dependiendo del entorno textual y del paradigma verbal en el que se encuentra el auxiliar (Markič 2013: 297). Esta p.v. abunda en el texto analizado, ya que es un instrumento imprescindible para expresar el paso del tiempo, como metáfora de la fugacidad de la vida: «Todo pasa, todo muere, y esta línea va fluyendo y se va yendo y yo con ella hacia la nada». (LRP 183)

En el ejemplo 5, el verbo auxiliar ir en pretérito perfecto simple de la p.v. aspectual ir + gerundio (fue desgarrando) marca el valor aspectual perfectivo. La p.v. expresa el avance gradual del evento visto desde una perspectiva global, focalizando el evento completo. Asimismo, la p.v. habian ido cayendo (ej. 6), con el auxiliar en pluscuamperfecto de indicativo, indica el desarrollo gradual del evento referido a un pasado remoto y focalizado en su totalidad, es decir, también desde una perspectiva global.

5 ¡Exacto el Liceo, se había acordado! Por lo menos esa batalla contra el mal de Alzheimer la había ganado. Una voz inefable velada de violeta fue desgarrando entonces el velo de las tinieblas del tiempo [...] (LRP 20)

6 Volando su avión sobre las nubes y la oscuridad del mar océano, las horas habían ido cayendo como las fichas de dominó, tumbándose las unas a las otras: la una se volvió las dos, las dos las tres, las tres las cuatro... (LRP 16)

En el fragmento 7, los recuerdos de Colombia y el flotar de los cadáveres en el río Cauca se comparan con el fluir de la gente en la Rambla. La p.v. iba arrastrando señala el progresar, el movimiento continuo, aspectualmente imperfectivo, ya que el evento no se ve como terminado (el auxiliar ir está en pretérito imperfecto de indicativo) sino como un perpetuo arrastrar. Todo el fragmento se sitúa en un marco de perspectiva cursiva, destacando la progresión y la duración (los paradigmas verbales están en imperfecto) excepto «el niño que fui» que sitúa el evento en el pasado desde una perspectiva global, perfectiva, ya que el verbo ser está en pretérito perfecto simple.

7 Rápido, rápido rápido iba arrastrando el río los decapitados en la lejana Colombia y por las calles de la Rambla la gente. El río era el Cauca, el de mi niñez, y la Rambla la de mi muerte, la de Barcelona. Y mientras el niño que fui seguía desde la orilla del río eterno el desfile de los cadáveres con gallinazos encima que les sacaban las tripas y salpicaban de sangre el agua pantanosa, el viejo que lo recordaba veía desde su mesa de café, viendo sin ver, el demabular interminable de la Rambla [...] (LRP 11-12)

En el fragmento 8, con la p.v. iba diciendo también se expresa el avance paulatino del evento, una intensificación gradual acompañada por una onomatopeya ( $t a c, t a c, t a c)$, un adverbio de modo (fatigadamente) y una locución adverbial (de tumbo a tumbo), es 
decir, un movimiento continuo y progresivo con el auxiliar en imperfecto que señala un evento imperfectivo. La p.v. de infinitivo me iba a morir traslada al protagonista a un momento posterior en la esfera del pasado, ya que el protagonista (en 1. ${ }^{\text {a }}$ persona) -no el narrador (hay un cambio de persona; el inicio del fragmento es narrado en 3. . $^{\text {persona)-, }}$ parte de un momento pasado (supe) hacia el futuro (me iba a morir).

8 Fibrilación ventricular, pulso filiforme, arritmia, lividez en la cara, y allá a lo lejos los ajenos murmullos del corazón, angustiados, distantes. Los síntomas los conocía muy bien porque ya los había vivido antes: cuando se le murió en sus brazos su perra la Bruja. La misma desesperanza, el mismo desamparo, y esa sensación de desastre inminente... «Tac ... tac ... tac...» iba diciendo el reloj incierto del corazón, de tumbo en tumbo, fatigadamente. ¿Fatigadamente? Pensé en los largos adverbios en «mente» del español, tan torpes, tan tontos, tan sosos, y en ese instante supe cómo me iba a morir: como Oudin, resolviendo un problemita pendejo de gramática. (LRP 11)

En el ejemplo 9, con el cambio del tiempo verbal, hay un cambio de perspectiva: de la global, que abarca la totalidad del evento (fue llevando), con el auxiliar en pretérito perfecto simple, a la cursiva, con el auxiliar en imperfecto, que focaliza el evento sin señalar el incio ni el final (iba llevando).

9 Acto seguido Colombia tomó la cabeza y el cuerpo, y con sus manos impunes, manchadas de sangre, los botó al Cauca, que se los fue llevando al Magdalena, que se los fue llevando al mar. Cuando todavía iban los cuerpos por el Cauca fue cuando el niño los vio desde la orilla: habían salido al flote hinchados y el río se los iba llevando, arrastrándolos en su corriente pantanosa con los gallinazos encima. (LRP 27)

$I r+$ gerundio también «permite visualizar el punto inicial o final del proceso del que se habla» (NGLE 2192). La visualización del punto inicial del proceso da lugar a valores aspectuales incoativos (ej. 10) que aparecen, sobre todo, en formas de imperativo (ej. 11) por tratarse de eventos aún no empezados «que el hablante se imagina ya en su principio y desarrollo progresivo posterior» (Gómez Torrego 1988: 161):

10 -Si es del hígado le doy tres meses. Si es del páncreas, uno. ¿Está el señor muy amarillo?

-Sí.

-Entonces bien pueden ir llamando a Gayasso. (LRP 113) 
11 Que no hablen más, que no sueñen, que no deliren, que se callen. Y que se vayan olvidando de la presidencia de Colombia porque esa no la van a oler nunca. (LRP 127)

Ir es un verbo de movimiento que implica un movimiento orientado, a diferencia de andar, que indica un movimiento no orientado y preferentemente se combina con «los predicados durativos que no están orientados a la consecución de una determinada meta o telos» (García Fernández 2006: 87). Andar + gerundio (12 y 13), p.v. semánticamente próxima a estar + gerundio, ya que no implica que el evento denotado por el verbo principal llegue a completarse, indica el desarrollo de un evento, expresa acciones continuas, habituales o reiterativas.

12 Ante la inminencia de su muerte qué le podía importar a él el juego de los vivos de andar separando para después unir, para después volver a separar, para después volver a unir... (LRP 108)

13 Si usted se muere ahora, deja de sufrir y se evita el calorón y andar vendiendo esas porquerías de libros. (LRP 170)

La p.v. aspectual venir + gerundio focaliza un evento desde su inicio hasta el punto central de su desarrollo sin indicar el final (García Fernández 2006: 268). Puede aparecer en ambas perspectivas, la global (ej. 14) y la cursiva (ej. 15). Se han encontrado pocos casos de esta p.v. en el texto analizado:

$14[\ldots]$ el cadáver se había venido descomponiendo, descomponiendo, y hoy día no llegaba ni a polvo de polvo. (LRP 54)

15 Un autobús de dos pisos repleto de turistas venía haciendo el tour de Barcelona. (LRP 152)

Esta p.v. puede cobrar un valor modal aproximativo, con idea de probabilidad (ej. 16):

16 ¿Cuátos espectadores habría? ¿Mil? ¿Cinco mil? ¿Diez mil? Cien si acaso en el teatrito improvisado, de suerte que puesto que eran tres los que hablaban les venía tocando de a treinta y tres y pico por cabeza. (LRP 182)

Una de las p.v. más usadas en español es estar + gerundio, p.v. aspectual «con significado de progresivo, es decir, de aquella variedad del aspecto Imperfecto en que se focaliza un único punto en el desarrollo de un evento.» (García Fernández 2006:136). 
Visualiza el evento presentado como ya comenzado pero no concluido cuando el auxiliar va en un tiempo verbal imperfectivo, valor frecuente en esta novela. Gómez Torrego (1988: 140) destaca que, cuando el auxiliar estar se encuentra en un tiempo perfectivo (pretérito perfecto simple o los tiempos compuestos), «se conjuntan el valor imperfectivo del gerundio con el perfectivo del auxiliar. De esta forma nos ofrece una imagen o idea durativa que se da por acabada en un momento determinado». Suelen acompañar esta p.v. referencias temporales (ej. 17):

17 El viejo nada descubrió. Nada en los muchos años que nos estuvo dando guerra. (LRP 71)

Si estas referencias no aparecen, la p.v. obtiene un carácter destelizador que «obliga a una interpretación en que no se alcanza la meta, a pesar, precisamente, de la forma perfectiva en que aparece el auxiliar» (García Fernández 2006:138). Matte Bon (1992, II: 160) mantiene que con esta perífrasis verbal el hablante no quiere presentar la realidad extralingüística objetiva y detalladamente sino que quiere comentarla, explicarla y que el momento emotivo cobra importancia. Con estar + gerundio también se actualiza la acción en la esfera del presente (ej.18 y 19) o del pasado (ej. 20 y 21) y, como ya se ha mencionado, se expresan valores durativos, prolongativos y progresivos (ej. 20 y 21), a veces también reiterativos y frecuentativos (Gómez Torrego 1988: 141-143) como en el ejemplo 22, en el que la p.v. va acompañada de un adverbial (paso a paso).

18 -iSe está pudriendo en vida el español, no se va a podrir el latín que está muerto! Dejémonos de güevonadas. (LRP 54)

$19-$-En qué está pensando, maestro? -le preguntó una de las señoritas triples viéndolo tan abstraído. (LRP 84)

20 Además la feria estaba resultando un desastre. (LRP 32)

21 La muerte no le iba a venir de arriba: le estaba llegando de adentro. (LRP 39)

22 Mañana hablaba. Pues paso a paso mañana se le estaba convirtiendo en hoy. (LRP 144)

La Rambla paralela empieza con un sueño y termina con el mismo: la muerte del protagonista. La novela comienza con el protagonista llamando por teléfono desde Barcelona a Colombia, a la finca Santa Anita, que desde hace años ya no existe más, queriendo hablar con su abuela, misiá Raquelita, que murió hace tiempo (ej. 23). Es un diálogo con una voz al teléfono en Colombia desde el lugar donde estuvo la finca, «entre Envigado 
Sabaneta, saliendo de Medellín» (LRP 9) y el protagonista que está durmiendo (muriéndose) en un hotelito de la calle Ferrán (LRP 12) de Barcelona. El diálogo inicial se presenta en la esfera del presente y se inicia con la perífrasis verbal estar + gerundio con el auxiliar en presente de indicativo (estoy llamando), que en este caso señala el valor aspectual progresivo y el temporal de presente actual. La última p.v. (estoy hablado) de este fragmento tiene el mismo valor, mientras que la p.v. ir a + infinitivo compuesto en la exclamación ;Cómo la van a haber tumbado! tiene un valor modal epistémico ${ }^{12}$ y no tempoaspectual que normalmente prevalece en la p.v. ir a infinitivo.

$23-$ ¿Estoy llamando al setenta y cinco ciento ventitrés?

-Sí pero no.

-¡Cómo! No le entiendo. ¿Ésa no es la finca Santa Anita?

-Aquí era pero ya no es: la tumbaron.

- ¿Cómo la van a haber tumbado!

- ¿Y por qué no? Todo lo tumban, todo pasa, todo se acaba. Y no sólo tumbaron la casa, ¿sabe? ¡Hasta la barranca donde se alzaba! La volaron con dinamita y únicamente dejaron el hueco. Un hueco vacío de aire.

-Señor, por favor, no se burle que le estoy hablando de larga distancia (LRP 9)

El diálogo final en la novela -en el sueño terminal- entre la voz telefónica de Colombia y el protagonista es casi idéntico al inicial: también se sitúa en el presente, solo que el interlocutor en este caso es una señorita, mientras que en el fragmento 23 es un señor. Se trata de «la angustiosa irrealidad del sueño» en la que «la arritmia tomó entonces el control del corazón.» (LRP 190). El sueño final es también el sueño eterno en el que se sumerge el protagonista, es decir, su muerte. Las dos p.v. estoy llamando, al inicio y al final de este fragmento (24), señalan el mismo valor como en el ejemplo 23. Aquí aparece la p.v. aspectual terminativa dejar de + infinitivo (deja de ser) que focaliza el final de la situación como una interrupción (García Fernández 2006: 117).

$24-¿$ ¿Adónde estoy llamando, señorita? ¿No es ése el setenta y cinco ciento ventitrés?

-Exacto. Ese mismo.

-O sea la finca Santa Anita, de doña Raquelita.

-Exacto. Aquí fue.

-¡Cómo que fue!

12 En este fragmento, algunas líneas más abajo, vuelve a aparecer la p.v. ir a + infinitivo compuesto en el mismo contexto comunicativo (exclamativo) indicando el valor epistémico de probabilidad y sorpresa: «¡Cómo se va a haber muerto, si es mi abuela!» (LRP 9) 
-Fue mas ya no es. Todo lo que algún día es otro día deja de ser. ¡O qué! ¿Cree que esto es eterno?

-Ay, señorita, no se burle que estoy llamando de larga distancia. (LRP 189)

La p.v. seguir + gerundio es muy frecuente en la novela, ya que acentúa el carácter de lo durativo y/o lo persistente de los recuerdos del protagnista. Se sitúa en el grupo de las p.v. de fase indicando la fase intermedia de la acción. Aparece en la mayoría de los casos en perspectiva cursiva (con el auxiliar en un tiempo verbal imperfectivo: presente o imperfecto como en los ejemplos 25, 26 y 27), y, en algunos casos, en perspectiva global (con el auxiliar en un tiempo verbal perfectivo: pretérito perfecto simple, como en el ejemplo 28).

25 Esperaba el loco un momento, como oyendo la voz interior, y luego se contestaba y seguía andando. (LRP 56)

26 Que se sentía muy feliz ese día aunque le seguían ardiendo los ojos. (LRP 78)

27 Y en tanto el viejo se moría, la Iglesia vil, mentirosa, asesina, impune, le seguía echando leña seca a la hoguera de la Plaza del Rey en que ardía Mossén Urbano por predicar sus encendidas verdades. (LRP 104)

28 Llevaba [Bruja, la perra] días de sufrimiento con los intestinos retorcidos hasta que una mañana, cuando ni él ni ella podían aguantar el dolor, le llegó por fin misericordiosa la Muerte. Pero sólo a ella, a él no. Él siguió cargando la cruz de su recuerdo por esta Vía Dolorosa. (LRP 123-124)

29 Detestaba la música, el radio, las motos, la televisión... Que el sol siguiera saliendo y poniéndose como un estúpido. (LRP 127)

Esta p.v. presenta una visión continuativa del evento en curso sin indicar la procedencia ni el destino del movimiento. Suele combinarse con predicados de naturaleza atélica ( ej. 25, 26, 31), mientras que, con predicados télicos (ej. 27, 29), predomina la lectura iterativa o frecuentativa. Se combina frecuentemente con las p.v. de modo: tener que + infinitivo (ej. 30), poder + infinitivo (ej. 31).

30 Ahora los viejos tenían que seguir aprendiendo como niños de teta. (LRP 66)

31 Cayó la lágrima en su copita de jerez, y para poder seguir llorando a gusto se tomó la copita de jerez con todo y lágrima. (LRP 101-102) 
Quedar(se) + gerundio es una construcción perifrástica que numerosos autores excluyen del grupo de las p.v.; sin embargo, en algunos casos actúa como p.v. para expresar el desarrollo de la acción a partir de su inicio. En el texto analizado aparecen dos casos, uno en forma pronominal (ej. 32) y el otro en forma no pronominal (ej. 33), ambos con el auxiliar en pretérito perfecto simple que indica perspectiva global.

32 Y me quedé viéndolos alejarse por la calle de las casetas bajo el sol poniente. ¿Qué irían pensando? ¿Qué irían diciendo? ¡Vaya Dios a saber! (LRP 63-64)

33 En Colombia, de tantos que había y de devaluarse tanto, «hijueputa» quedó valiendo nada. Ayer un insulto, hoy significaba simplemente persona, tipo, un tal, un cual, un fulano, usted, su papá, su tío, yo, el Padre, el Hijo, el Espíritu Santo, alguien y nadie, mucho y poco, todo y nada. (LRP 97)

En el texto aparecen algunos ejemplos de la p.v. acabar/terminar + gerundio que indica el final de una serie de eventos implícitos o explícitos (ej. 34 y 35). Son más frecuentes en el texto sus formas sinónimas acabar/terminar por + infinitivo. García Fernández (2006: 59) las define como perífrasis discursivas que desempeñan la función de ordenador de cierre en el texto.

34 Los muertos estamos a merced de los vivos, de su buena voluntad: si tienen rencor contra uno, nos borran. Es más, ni rencor terminan teniendo. Algo peor: olvido. Y el olvido es viento. (LRP 31-32)

35 En cuanto a la luz, de donde viene Lucifer, su dueño, viaja siempre a contracorriente de la gravedad tratando de escapársele, pero no puede: tarde o temprano acaba rebotando contra algo. (LRP 149)

\section{CONCLUSIÓN}

En este estudio sobre las p.v. de gerundio en la novela La Rambla paralela se ha querido destacar el papel de las perífrasis verbales de gerundio en la creación de una atmósfera de un movimiento imparable, de la imagen del tiempo como un río que fluye hacia la nada, pero que, en su permanente fluir, parece dar vueltas en redondo: «Ya no sabía si estaba desandando el camino andado, o si era que el tiempo de ocioso se había puesto a girar en redondo como un gato que quisiera agarrarse la cola» ( $L R P 166)$.

Como ya se ha destacado, las p.v. de gerundio «presentan como rasgo general, la acción vista en su desarrollo, en su transcurso (aspecto 'cursivo') [...].» (Yllera 1999: 3393). El mismo gerundio, cuando actúa como verbo «es una forma aspectualmente 
imperfectiva o progresiva, que expresa la acción o el proceso denotado por el verbo en su desarrollo o sin su término [...]» (Fernández Lagunilla 1999: 3456) y contribuye al valor cursivo de las perífrasis verbales de gerundio. Además, casi todos los auxiliares de las p.v. de gerundio, excepto estar, acabar, terminar, empezar y algunos más, se usan también como verbos plenos de movimiento (andar, ir, venir, seguir...) y, aunque pierden su valor léxico, transmiten a la p.v. un cierto valor de dinamismo. El carácter progresivo o gradual hace que estas p.v. sean un importante recurso estilístico (Gómez Torrego 1988: 163). En el texto analizado las p.v. progresivas, sobre todo estar + gerundio (ej. 36 y 37) e $i r+$ gerundio (ej. 37), acentúan el paso inevitable e imparable del tiempo, el fluir de la vida hacia la muerte, el envejecer, el recuerdo y el olvido, que son temas recurrentes de la obra de Vallejo:

36 Día a día nos estamos muriendo todos de a poquito. (LRP 13)

37 Al nacer ya nos estamos muriendo. Todo pasa, todo muere, y esta línea va fluyendo y se va yendo y yo con ella hacia la nada. (LRP 183)

Las p.v. de gerundio con valores de movimiento lento y paulatino acompañadas de adverbiales (día a día, de a poquito en el ejemplo 36 y en muchos otros) o, como en el caso de los ejemplos 38, 39 y 40, con las repeticiones del verbo auxiliado en gerundio, impregnan la prosa de un ritmo repetitivo con imágenes prolongativas.

38 El aguardiente se lo tomaron, las ilusiones se evaporaron y la vida se fue pasando, pasando, pasando, acabando, acabando, acabando. (LRP 107)

$39[\ldots]$ con los ojos llorosos por el polvo que le echaba en la cara su amigo el viento se fue yendo, yendo, yendo hacia atrás en un globo, surcando el cielo de vuelta a su niñez $[\ldots]$ (LRP 184)

40 Las flores se van marchitando, marchitando, marchitando mientras los gusanos nos van comiendo, nos van comiendo, nos van comiendo...(LRP 188)

La Rambla paralela se presenta como un río de gente en permanente fluir, como metáfora del paso del tiempo y de la vida. El análisis de las perífrasis verbales de gerundio en la novela de Fernando Vallejo ha mostrado que las p.v. contribuyen en gran medida a crear esta imagen. 


\section{BIBLIOGRAFÍA}

\section{Texto citado}

VALLEJO, Fernando (2002) La Rambla paralela. Madrid: Alfaguara.

\section{Referencias bibliográficas}

Asociación de Academias de la Lengua Española/Real Academia Española (2009) Nueva gramática de la lengua española. Madrid: Espasa.

BATIUKOVA, Olga/Elena DE MIGUEL (2013) Tratamiento lexicográfico de verbos de movimiento con significado amplio. Actas del XLI Simposio de la SEL. Valencia: Universitat de Valéncia, 439-450.

COMRIE, Bernard (1976) Aspect. An Introduction to the Study of Verbal Aspect and Related Problems. Cambridge: Cambridge University Press.

COSERIU, Eugenio (1980) Aspect verbal ou aspects verbaux? Quelques questions de théorie et de méthode. La notion d'aspect, Colloque Organisé par le Centre d'Analyse Syntaxique de l'Université de Metz. Paris: Klincksieck,13-25.

DE MIGUEL, Elena (2012) Verbos de movimiento en predicaciones sin desplazamiento espacial. Verba Hispanica XX, 185-209.

FERNÁNDEZ LAGUNILLA, Marina (1999) Las construcciones de gerundio. I. Bosque/V. Demonte (dirs.) Gramática descriptiva de la lengua española. Madrid: Espasa Calpe, 3444-3503.

FORERO, Gustavo (2005) La metonimia de Colombia en La Rambla paralela de Fernando Vallejo. Campus No. 3, 1-21. www.fuac.edu.co/recursos_web/descargas/grafia/metonimia.pdf

FORERO GÓMEZ, Andrés Fernando (2011) Crítica y nostalgia en la narrativa de Fernando Vallejo: una forma de afrontar la crisis de la modernidad. $\mathrm{PhD}$ (Doctor of Philosophy) thesis, University of Iowa. http://ir.uiowa.edu/etd/964

GARCÍA FERNÁNDEZ, Luis (dir.) (2006) Diccionario de perifrasis verbales. Madrid: Gredos.

GÓMEZ TORREGO, Leonardo (1988) Perifrasis verbales. Madrid: Arco/Libros.

GÓMEZ TORREGO, Leonardo (1999) Los verbos auxiliares. Las perífrasis verbales de infinitivo. I. Bosque/V. Demonte (dirs.) Gramática descriptiva de la lengua española. Madrid: Espasa Calpe, 3323-3389.

MARKIČ, Jasmina (2013) El día en que lo iban a matar. Las perífrasis verbales en Crónica de una muerte anunciada. Colindancias 4, 289-303. https://colindancias.uvt.ro/ index.php/colindancias/article/view/26/23

MARKIČ, Jasmina (2020) El ir y venir de La Rambla paralela. Studia Romanica et Anglica Zagrabiensia 65, 351-358. 
MATTE BON, Francisco (1992) Gramática comunicativa del español. Tomos I, II. Madrid: Difusión.

MIKLIČ, Tjaša (1983) L'opposizione italiana perfetto vs. imperfetto e l'opposizione slovena dovršnost vs. nedovršnost nella verbalizzazione delle azioni passate. Linguistica XXIII, 53-123.

YLLERA, Alicia (1999) Las perífrasis verbales de gerundio y de participio. I. Bosque/V. Demonte (eds.) Gramática descriptiva de la lengua española Madrid: Espasa Calpe, 3391-3441.

\section{POVZETEK}

\section{O GLAGOLSKIH PERIFRAZAH Z GERUNDIJEM V ROMANU LA RAMBLA PARALELA FERNANDA VALLEJA}

Pričujoči članek se posveča analizi glagolskih perifraz z gerundijem in njihovimi vlogami pri ustvarjanju specifičnega sloga kolumbijskega pisatelja Fernanda Valleja v delu La Rambla paralela (Vzporedna ulica $\mathrm{v}$ slovenskem prevodu Ferdinanda Miklavca), enem od njegovih avtobiografskih romanov, v katerem je protagonist oz. pripovedovalec prav tako Fernando, njegov alter ego. V uvodnem delu je govora o pripovedni strukturi romana in o ponavljajočih se temah, kot je na primer minevanje časa, ko se sedanjost in preteklost zlijeta v prihodnost, ki vodi v smrt. Naslov dela je pomenljiv in namiguje na vzporednico, po kateri se protagonist giblje med življenjem in smrtjo, med sedanjostjo in preteklostjo, med Barcelono, glavnim mestom Katalonije, in Medellínom, prestolnico kolumbijske pokrajine Antioquia.

Drugi del prispevka obravnava glagolske perifraze z gerundijem, ki prikazujejo dejanja v poteku in imajo različne aspektualne, časovne in modalne vrednosti. Pomožni glagoli teh glagolskih perifraz so pogosto glagoli gibanja, ki kljub temu, da delno ali v celoti izgubijo svoj polni leksikalni pomen, ohranjajo pridih dinamike. Analizirana aspektualna glagolska perifraza ir + gerundio signalizira postopno napredovanje določenega dejanja in se pogosto pojavlja skupaj s prislovnimi določili za progresivnost, kot so progresivamente, poco a poco, gradualmente. Občutje počasnega poteka dejanj, ki ga pripovedovalec pričara z glagolskimi perifrazami z gerundijem, predvsem $\mathrm{z}$ ir + gerundio, sproža nastajanje podob, ujetih $\mathrm{v}$ trenutke počasnega napredovanja in poudarja neustavljivo minevanje časa, kot ga občuti človeško bitje. Vzporedna ulica se kaže kot reka ljudi v neprestanem gibanju, kot metafora za minevanje časa in življenja, hkrati pa tudi kot ponavljajoče se gibanje, neprestano odhajanje in prihajanje.

Ključne besede: glagolske perifraze z gerundijem, glagoli gibanja, aspektualnost, časovnost, življenje in smrt 


\section{ABSTRACT \\ ON THE VERBAL PERIPHRASES OF GERUNDIO IN LA RAMBLA PARALELA BY FERNANDO VALLEJO}

The article deals with the verbal periphrases with gerunds and highlights their role in the specific style of the Colombian writer Fernando Vallejo in one of his autobiographical novels, La Rambla paralela. The introductory part of the study presents the narrative structure of the novel and its recurrent themes, such as the passage of time, as the present and past merge into a future that leads to death. The title of the work is meaningful and hints at a parallel along which the protagonist moves between life and death, between his present and past, between Barcelona, the capital of Catalonia, and Medellín, the capital of the Colombian Department of Antioquia.

The second part of the paper analyses some aspectual verb periphrases with gerunds. The auxiliary verbs are often verbs of movement, which, although they partially or completely lose their full lexical meaning, retain a touch of dynamism. The verb periphrasis ir + gerundio signals the gradual progression of actions and often occurs together with proverbial determinants for progressivity. The feeling of a slow course of action, conjured by the narrator with these verb periphrases with gerund, especially with ir + gerundio, triggers the creation of images captured in moments of slow progress and emphasizes the unstoppable passage of time as felt by human beings. La Rambla paralela ('the parallel street') manifests itself as a river of people in permanent flow, as the metaphor for the passage of time and life, but also as a recurrent movement of coming and going.

Keywords: verbal periphrases of gerundio, verbs of movement, aspect values, temporal values, life and death

\section{RESUMEN}

\section{SOBRE LAS PERÍFRASIS VERBALES DE GERUNDIO EN LA RAMBLA PARALELA DE FERNANDO VALLEJO}

El presente artículo se dedica a analizar las perífrasis verbales de gerundio y a destacar el papel que estas estructuras desempeñan en el estilo específico de Fernando Vallejo en una de sus novelas autobiográficas, La Rambla paralela. En la introducción se presentan brevemente la estructura narrativa de la novela y sus temas recurrentes como el paso del tiempo en el que el presente y el pasado se diluyen en un futuro que lleva a la muerte. El título de la obra es significativo e implica un paralelismo en el que se encuentra el protagonista que se mueve entre la vida y la muerte, entre su presente y su pasado, entre Barcelona y Medellín. 
La segunda parte se centra en el análisis de las perífrasis verbales de gerundio que aparecen en el texto. Estas estructuras verbales señalan un evento en su curso e indican diferentes valores tempoaspectuales y modales. Los auxiliares son frecuentemente verbos de movimiento que, aunque pierden parcial o totalmente su valor pleno de movimiento, mantienen un matiz de dinamicidad. Así, por ejemplo, la perífrasis ir + gerundio, además de su valor aspectual de progresión lenta, tiene un fuerte valor expresivo que ayuda a crear imágenes de eventos durativos y progresivos destacando el fluir imparable del tiempo. De esta manera respalda la temática principal de la novela que se presenta como un río de gente en un fluir permanente, como metáfora del paso del tiempo y de la vida pero también de un movimiento recurrente de ida y vuelta.

Palabras clave: perífrasis verbales de gerundio, verbos de movimiento, valores aspectuales, valores temporales, vida y muerte 